\title{
Las rutas del libro atlántico: libros enviados en el navío de Honduras (1557-1700) ${ }^{1}$
}

\author{
Pedro Rueda Ramírez \\ Universidad de Barcelona
}

En este trabajo se analizan los envíos de libros en el navío de Honduras, que viajaba entre Sevilla y los puertos atlánticos de la costa centroamericana. Examinamos una muestra de 52 registros de navios, que suponen un 20\% del total. Esto nos ha permitido localizar lotes de libros declarados en 34 barcos, en los que se han encontrado 130 envíos de libros. Este conjunto ayuda a detectar las claves del circuito de llegada de los libros, muy poco conocido, por medio de comerciantes, libreros y particulares. El estudio de los intermediarios también permitió localizar algunas de las redes que intervienen en ese tráfico de libros. Por último, el estudio de los títulos embarcados ha llevado a encontrar una muestra significativa de los textos impresos en Europa que llegaron en los siglos XVI y XVII al área de Guatemala y Honduras.

Palabras Clave: Comercio de libros, libreros, mercaderes, lectura, literatura de entretenimiento, Carrera de Indias, Honduras, Guatemala.

In this work we analyze shipments of books in the Honduras route, which traveled between Seville and Central America's Atlantic ports. We analyze a sample of 52 registers from the Honduras fleet, comprising 20 percent of the total. This has allowed us to locate the book lots declared for 34 ships, a total of 130 book shipments. This group of materials reveals key features of the books' little known arrival circuit through merchants, booksellers, and private individuals. Study of these intermediaries reveals some of the networks involved in the book trade. Study of the titles sent moreover reveals an important sample of European printed texts that arrived in the area of Guatemala and Honduras during the sixteenth and seventeenth centuries.

KEYwORDS: Book trade, booksellers, merchants, reading, literature of leisure, Transatlantic trade, Honduras, Guatemala.

El impreso irrumpió por doquier en el mundo moderno. Los textos emborronados con la escritura artificial de los tipos salieron de las prensas para circular, su fin no fue otro que el de venderse e intercambiarse. El tex-

1 Este trabajo se ha realizado en el marco del equipo I+D+i "Normas y transgresiones culturales en el Siglo de Oro", financiado por el Ministerio de Educación y Ciencia (HUM2005-07069-C0502); más información en http://www.uco.es/investiga/grupos/sigloro/index.htm. 
to impreso fue un producto cultural con rasgos novedosos que pronto encontraría su lugar en el mercado a uno y otro lado del Atlántico. Desde fechas tempranas la producción de las imprentas europeas contó con una importante vía de negocio en el territorio americano gracias a la Carrera de Indias. ${ }^{2}$ A ello contribuyó, sin duda, la escasez de impresos realizados en el Nuevo Mundo y la tardía implantación de las imprentas en la mayoría de los lugares. En este sentido el área centroamericana es, en gran medida, un ámbito sin prensas, dependiente de la producción mexicana, poblana y europea. Los mismos lazos del impresor José de Pineda Ibarra, establecido en 1660 en Santiago de Guatemala, marcan una pauta de relación con México. En su testamento de 1680 indicaba que debía a Paula de Benavides, viuda del impresor mexicano Bernardo Calderón, 150 pesos "que siendo su oficial y trabajando en su casa, me los prestó en reales de diferentes partidas". ${ }^{3}$ En esta tesitura el negocio de la imprenta y de la librería quedará, en muchos casos, como una más de las actividades económicas desempeñadas por estos profesionales del libro. El caso de Pineda Ibarra resulta, de nuevo, revelador. Reconocía deudas pendientes por la compra de una tenería, o bien por negocios con harinas, pero también una deuda de 411 pesos "para comprar la librería del señor doctor don Jerónimo de Vega y Vich, oidor que fue de esta Real Audiencia". Sin duda fue un buen negocio, pues consiguió los libros sin desembolsar un peso, a cuenta de partir las ganancias por mitad, y logró un fondo considerable de 334 libros que aún tenía en su poder en 1680.

2 Analiza la llegada de vendedores de libros a Lima Hampe Martínez, Teodoro: Bibliotecas privadas en el mundo colonial: La difusión de las libros e ideas en el virreinato del Perú (siglos XVIXVII), Vervuert, Frankfurt; Iberoamericana, Madrid, 1996. También se ocupa de estos asuntos Guibovich Pérez, Pedro: "Libros para ser vendidos en el virreinato del Perú a fines del siglo XVI", Boletín del Instituto Riva-Agüero, 13, Lima, 1984-1985, págs. 85-114. En el caso de las ciudades mexicanas, además de los repertorios clásicos, contamos con trabajos especializados como el de Castro Morales, Efraín: "Libros del siglo XVI en la ciudad de Puebla de los Ángeles", en Libros europeos en la Nueva España a fines del siglo XVI. Una contribución a la estratigrafía cultural, Franz Steiner Verlag, Wiesbaden, 1973, págs. 111-121. Una revisión general en Rivas Matas, Emma: "Impresores y mercaderes de libros en la ciudad de México, siglo XVII", en Carmen Castañeda (coord.): Del autor al lector. I. La historia del libro en México y II. La historia del libro. CIESAS. CONACyT; Miguel Ángel Porrúa, México, 2002, págs. 71-102. Una visión de conjunto en Calvo, Hortensia: "The Politics of Print. The Historiography of the Book in Early Spanish America”, Book History, 6, 2003, págs. 277-305.

3 Esta cita y las siguientes están tomadas de la transcripción del documento notarial publicado por Medina, José Toribio: La imprenta en Guatemala, Santiago de Chile, Impreso en casa del Autor, 1910, págs. LXIII-LXV. También se ocupa por extenso de estas imprentas Medina, José Toribio: Historia de la imprenta en los antiguos dominios españoles de América y Oceanía, Tomo II [en línea], Biblioteca Virtual Miguel de Cervantes, Alicante, 2000, págs. 119-167. Ed. digital basada en la de Santiago de Chile, 1958. http://www.cervantesvirtual.com. 
Los impresores y los libreros que se asentaron en las ciudades centroamericanas tuvieron una clara perspectiva de las dificultades que encontrarían para consolidar sus negocios en un territorio en el que existía una clientela potencial minoritaria, aunque dependiente de sus habilidades. ${ }^{4} \mathrm{El}$ tráfico comercial ligado a la Carrera de Indias les facilitó una vía para obtener libros, al igual que los burócratas en sus viajes en busca de un nuevo cargo podían aprovechar para incrementar su biblioteca durante su estancia en España o en México. De la misma manera los religiosos solían aprovechar el viaje a la Corte o a Roma, o bien pedir los libros que deseaban tener en sus conventos, como hicieron los dominicos de Coyoacán. ${ }^{5}$

Los libreros centroamericanos también solicitaban las novedades a sus colegas sevillanos, y de igual modo, podían acordar la compra de lotes en Sevilla con los mercaderes que traficaban en el navío de Honduras. Estos encomenderos resultaron una baza fundamental de todo el tráfico, pues controlaban la complicada maquinaria de la Carrera de Indias. Acudir a ellos era una garantía para lograr que el navío trajera en su tornaviaje aquellos preciados volúmenes que necesitaban para sus estudios o sus librerías.

La posibilidad que brindaba el tráfico atlántico fue aprovechada para surtir de libros las tiendas, los colegios, la universidad, los conventos e iglesias y las bibliotecas particulares. En cualquier caso es evidente que había grandes diferencias entre las ciudades y las zonas campesinas, así como entre las áreas portuarias mejor abastecidas y las zonas de interior. El obispo de Honduras se quejaba al rey de la falta de medios "porque como Guatemala es tierra tan rica y está tan misera, no ay clérigo que quiera parar

4 El catálogo de la producción bibliográfica realizado en 1897 por Juan Enrique O’Ryan comprendía, entre 1660-1700, un total de 39 obras. La descripción detallada en Bibliografía guatemalteca de los siglos XVII y XVIII, $2^{\mathrm{a}}$ ed., Editorial del Ministerio de Educación Pública José de Pineda Ibarra, Guatemala, 1960. Este libro, y otros de la misma fecha, se publicaron con motivo del III Centenario de la introducción de la imprenta en Centroamérica, como el de Reyes Monroy, José Luis: Acotaciones para la historia de un libro (el puntero apuntado con apuntes breves), Editorial del Ministerio de Educación Pública José de Pineda Ibarra, Guatemala, 1960. Este mismo autor publicó un complemento a los catálogos anteriores en Bibliografía de la imprenta en Guatemala, Editorial del Ministerio de Educación Pública José de Pineda Ibarra, Guatemala, 1969. La posesión del libro en estos territorios no cuenta con trabajos de conjunto. Un erudito estudio de caso en Barrientos Grandon, Javier: "Librería de Don Sebastián Calvo de la Puerta (1717-1767). Oidor de la Real Audiencia de Guatemala”, Revista de estudios histórico-jurídicos [en línea], 21, 1999, págs. 337-373, http://www.scielo.cl/scielo.php.

5 Wagner, Klaus: "Libros para el convento de Santo Domingo de Coyoacán", Historiografía y Bibliografía Americanista, 23, Sevilla, 1979, 6 págs. Los libros de los eclesiásticos tuvieron una importancia crucial. Un estudio en Solano, Francisco de: "Los libros del misionero en Guatemala", Missionalia Hispanica, XX, 60, 1963, págs. 319-350. 
en ella" y le pide merced "para que le hagan retablos, caliçes, ornamentos, libros de canto y otras cosas necesarias". ${ }^{6}$ Los Cabildos y los obispos procuraban abastecer sus territorios con las obras básicas de la liturgia, y para lograrlo podían acudir a la Corona o bien utilizar el dinero recaudado a sus feligreses. El negocio para los libreros no acababa aquí ya que los párrocos necesitaban en sus iglesias libros blancos para el asiento de los bautizos, bodas y defunciones. El comercio del papel, la tinta y otros materiales necesarios formaba también parte del negocio de los libreros. En estos territorios los libros podían quedar en uso un largo tiempo, sin que les afectaran las preocupaciones de revisión que demandaban primero los obispos mexicanos y luego la Inquisición de ese virreinato, a partir de 1571. De hecho, cuando en 1586 el comisario de Chiapas recibió el encargo de revisar los libros escribió que "en lo que toca al trabajo de expurgar los libros, bien vemos que será grande, y así habemos permitido cualquier ayuda [...] que cada uno enmiende su libro por el cathálogo".

Los impresos, las estampas, los formularios de las notarías, así como la variedad de la producción efímera, circularon y se usaron abundantemente. La letra impresa en sus múltiples variantes, los grabados xilográficos y los adornos tipográficos fueron cotidianos a los habitantes de las ciudades y aún lo fueron más conforme se iba consolidando la colonización. Lejos quedaban las estelas y la escritura maya que vió Diego García de Palacio, pues en "Copán, están unas ruinas y vestigios de gran poblazón [...] y una piedra grandísima en figura de águila, y hecho en su pecho un cuadro de largo de una vara y en él ciertas letras que no se sabe qué sea". El olvido y el desconocimiento de esa otra escritura de "ciertas letras" supuso una condición más para la colonización.

6 Aguiluz Milla, Edwin, (ed.): Iglesia y sociedad colonial en Honduras: Documentos del siglo XVI, Obispado de Choluteca, Honduras, 1994, págs. 297-298. Una consecuencia de estas peticiones es el intenso tráfico de pinturas, esculturas, piezas de orfebrería y otras que recoge Luján Muñoz, Jorge: "Ejemplos de comercio de obras de arte entre España y el reino de Guatemala en la colonia", Archivo Español de Arte, 51, 202, 1978, págs.155-163. Este tipo de negocios atlánticos son habituales en los artistas sevillanos, así en el testamento de bienes de Alonso Vázquez de 1607 este pintor afirma " que de la çiudad de Guatemala se me ynviaron çient pesos para colores"; transcribe el documento Palomero Páramo, Jesús: "Las últimas voluntades y el inventario de bienes del pintor Alonso Vázquez", Anales del Instituto de Investigaciones Estéticas, 86, 2005, págs. 169-202.

7 Libros y libreros en el siglo XVI. Selección de documentos y paleografía de Francisco Fernández del Castillo, 2a ed., FCE, México, 1982, págs. 337-340. La acción inquisitorial es descrita por Chinchilla Aguilar, Ernesto: La Inquisición en Guatemala, Ministerio de Educación Pública, Guatemala, 1953, págs. 187-196, e incluye la lista de libros expurgados o recogidos por la Inquisición, págs. 299-312. 


\section{El navío de Honduras}

La Casa de la Contratación se encargó de organizar la flota que se dirigiría a Veracruz. Desde 1564 salía en el mes de abril (y en mayo a partir de 1582), y a ella podían unirse el navío de Honduras y los barcos destinados a las Antillas. ${ }^{9}$ El viaje en el navío resultaba incómodo, lento y peligroso. El obispo de Honduras escribió su primera carta al emperador Carlos V desde Trujillo en 1545 y no dudó en anotar al margen "tarde en my viaje de Sevilla aquí XLV días". ${ }^{10}$ Un dato que resume, en su brevedad, las difíciles jornadas de navegación atlántica. El tráfico a tierras centroamericanas quedó vinculado a un trasiego de hombres para el gobierno, misioneros y mercancías que pronto permitieron consolidar un intercambio de materias primas por toda una gama de productos europeos de importación. Desde Trinidad de Sonsonete, Francisco López de Salazar escribió a su hermana invitándola a ir a tierras americanas y en la carta trataba asimismo sobre los negocios, pues éstas eran, además de un lazo de unión, un buen mecanismo de información mercantil. Le informó de que "va tratado con Jerónimo de Pereda que el año que viene le envíe tinta, que es la mercadería de esta tierra". ${ }^{11}$ En esto tenía toda la razón, pues los libros se pagaron con añil en muchas ocasiones. La franja costera del Golfo de Honduras, en la bahía de Amatique, el puerto de Trujillo, Puerto Caballos y Santo Tomás de Castilla fueron puntos de arribada de la "nao de Honduras". Aunque el tráfico de navíos fue, en opinión de Pérez Brignoli, "azaroso y a menudo esporádico", ${ }^{12}$ Chaunu apunta que "la continuidad del movimiento con Honduras es

8 García de Palacio, Diego: Carta-Relación a Felipe II sobre la provincia de Guatemala, 8 de marzo de 1576, ed. facsimilar y modernizada de $\mathrm{M}^{\mathrm{a}}$ del Carmen León Cazares, Martha Ilia Nájera C. y Tolita Figueroa, Universidad Nacional Autónoma de México, México, 1983, págs. 89-90.

9 Lorenzo Sanz, Eufemio: Comercio de España con América en la época de Felipe II, 2 ts. Servicio de Publicaciones de la Diputación Provincial, Valladolid, 1980, T. I, págs. 276-278. Los aspectos legales del tráfico comercial los describe Caballero Juárez, José Antonio: El régimen jurídico de las armadas de la Carrera de Indias: siglos XVI y XVII, Universidad Nacional Autónoma de México, México, 1997. También en González Sánchez, Carlos A.: "La Casa de la Contratación y la historia cultural”, en Acosta, Antonio; González, Adolfo y Vila, Enriqueta (coords.): La Casa de la Contratación y la navegación entre España y las Indias, Universidad de Sevilla, EEHA, Fundación El Monte, Sevilla, 2003, págs. 543-566.

10 Aguiluz Milla, Edwin: Iglesia y sociedad”, pág. 203. Recoge varios testimonios Martínez, José L.: Pasajeros a Indias. Viajes trasatlánticos en el siglo XVI, $3^{\mathrm{a}}$ ed., FCE, México, 1999.

11 Otte, Enrique: Cartas privadas de emigrantes a Indias, 1540-1616, Junta de Andalucía, Consejería de Cultura, Sevilla, 1988, págs. 231-233, n. ${ }^{\circ}$ 256. Carta de 1598.

12 Pérez Brignoli, Héctor: Breve historia de Centroamérica, Alianza, Madrid, 1985, pág. 40. 
el mismo de Nueva España", ${ }^{13}$ pues seguía el ritmo de las flotas y dependía de la buena marcha del grueso de los navíos.

La carga de mercancías en los navíos de Honduras permite detectar quiénes fueron los cargadores que enviaron frangotes y cajones de libros encaminados a la vertiente atlántica de la franja centroamericana. El proceso de carga seguía idénticos procedimientos que el resto de la flota de Nueva España. Los cargadores debían acudir con los cajones y los documentos a la Aduana, donde quedaban depositados los bultos hasta que se embarcaban en el navío en el que realizarían el viaje atlántico. De aquí el cargador iba con los papeles a la Contaduría de la Casa de la Contratación, en la que se van anotando los pagos de impuestos (almojarifazgo, avería de armada, consulado, etc.). Una vez resuelto el complicado papeleo, los libros debían someterse a un control paralelo por parte de los inquisidores sevillanos. El cargador tenía que, de este modo, seguir un trámite un tanto enrevesado antes de lograr sacar de la Aduana los libros encajonados y marcados con un sello de cera que garantizaba la revisión por parte de un calificador del Santo Oficio.

El porcentaje de idas a estas áreas (tabla I) ofrece unos resultados escasos en comparación con las cifras de miles de navíos de la Carrera de Indias que fueron a los puertos de Veracruz, Nombre de Dios, Portobelo o Cartagena. No obstante, el conjunto de 260 navíos que viajaron entre 1538 y 1700 suma una cantidad de viajes más que notable, que abrió las posibilidades a la llegada de libros desde Europa. En este trabajo queremos aportar una aproximación al estudio del comercio del libro en la zona de Honduras y Guatemala investigando una muestra de 52 registros de barcos (un 20\% del total). En 34 de ellos navegaron libros declarados como mercancía. Otro asunto bien distinto sería el de los libros que pudieran llevar los pasajeros consigo. En este trabajo tan sólo aparecerán reflejados los libros incluidos en las declaraciones juradas realizadas por los cargadores. Este era un testimonio preceptivo y obligatorio para poderse embarcar bajo registro, pues hay un proceso administrativo y un cobro de impuestos que viene fijado en el articulado de las Ordenanzas de la Casa de la Contratación. El libro aparece, de este modo, tratado como una mercancía

13 Chaunu, Pierre: Sevilla y América (siglos XVI y XVII), Universidad de Sevilla, Sevilla, 1983, págs. 137-140. También Chaunu, H. et P.: Séville et l'Atlantique, première partie: deuxième partie, partie interprétative. Structures et conjocture de l'Atlantique espagnol et hispano-américain, t. VIII(1), les structures, SEVPEN, Paris, 1959, págs. 847-897. 
más de las declaradas en la Aduana de la ciudad de Sevilla para cargarse con destino a América. ${ }^{14}$

\section{TABLA I}

EL NAVÍO DE HONDURAS

\begin{tabular}{cccc} 
Años & $\begin{array}{c}\text { Total navios de ida } \\
\text { a Honduras }\end{array}$ & $\begin{array}{c}\text { Registros de Navíos } \\
\text { analizados }\end{array}$ & $\begin{array}{c}\text { Navíos con libros en } \\
\text { las declaraciones }\end{array}$ \\
\hline $1538-1550$ & 27 & - & - \\
$1551-1560$ & 28 & 1 & - \\
$1561-1570$ & 16 & - & - \\
$1571-1580$ & 15 & 2 & 2 \\
$1581-1590$ & 20 & 9 & 4 \\
$1591-1600$ & 27 & 12 & 11 \\
$1601-1610$ & 27 & 1 & 1 \\
$1611-1620$ & 28 & 6 & 4 \\
$1621-1630$ & 21 & 4 & 4 \\
$1631-1640$ & 16 & 7 & 3 \\
$1641-1650$ & 8 & 6 & 1 \\
$1651-1660$ & 6 & 5 & 3 \\
$1661-1670$ & 5 & 3 & 1 \\
$1671-1680$ & 5 & 2 & - \\
$1681-1690$ & 8 & - & 35 \\
$1691-1700$ & 3 & 54 &
\end{tabular}

Las cifras obtenidas de la muestra de 34 navíos se exponen en la tabla II. En los años que transcurren entre el primer navío estudiado de 1557 y el último de 1687 la cata de navíos analizados muestra la notable cantidad de 130 cargadores de libros (tabla II). En los años iniciales de 1551 a 1560 se aprecia un lento despegue. En esta primera etapa los envíos son pequeños, generalmente de menudencias con textos básicos (cartillas, coplas, etc.). Las ausencias más notables se deben, claro está, a los pocos

14 La crítica de la fuente en Rueda Ramírez, Pedro: Negocio e intercambio cultural: El comercio de libros con América en la Carrera de Indias (siglo XVII), Universidad de Sevilla; Diputación de Sevilla; Escuela de Estudios Hispano-Americanos, Sevilla, 2005. 
registros analizados entre 1561 y 1600 , algo que esperamos subsanar en nuevas investigaciones. En todo caso, las cotas más altas de envíos a Honduras coinciden, en líneas generales, con los mejores momentos de remisiones de libros a América a principios del siglo XVII. ${ }^{15}$ El tráfico comercial de este producto cultural en la primera década apareció con fuerza, fue un momento de envíos abundantes, tan sólo en 1608 hay 23 cargadores que declaran libros. En todo caso éste fue un año excepcional en todo el conjunto de la flota de Nueva España, con envíos impresionantes si tenemos en cuenta la caída del tráfico observada a partir de 1610. Esta fecha y la de 1620 suponen un punto de inflexión que también se refleja en los envíos a un área periférica como Honduras. A partir de 1610 las cifras de cargadores de libros son muy discretas hasta llegar a un tope de 10 en la década de los setenta debido, sobre todo, al navío que va en 1678. El estudio de Lutgardo García Fuentes permite seguir la pista al total de barcos que realizaron la travesía en la segunda mitad del siglo XVII y en su trabajo se contabilizan los cajones de libros remitidos entre 1650 y 1699. Es una unidad de medida discutible pero que permite un primer acercamiento. En el total del tráfico comercial encuentra 6.636 cajones, de ellos fueron a Nueva España un $31,8 \%$, esto es, 2.116, y a Honduras 141, entre 1660 y 1699. El tráfico de libros a Honduras supuso, de acuerdo a estas cifras, un $2 \%$ del total de los envíos de cajones con libros. Es un total discreto, pero no debemos olvidar que el mercado potencial es más limitado y que los cauces del navío de Honduras no eran la única vía de llegada de libros. El desglose que ofrece este investigador al analizar todos los navíos (tabla III), y no únicamente la muestra que aquí ofrecemos de manera más detallada, permite evaluar un primer acercamiento.

Teniendo presente que el registro es una vía comercial de transferencia de mercancías con otras prioridades (los libros no dejan tantos beneficios frente a otras mercancías), que tan sólo revisamos un $20 \%$ del total de navíos y que no se cuentan los libros que fueron entre las pertenencias de los pasajeros ni, claro está, los que pudieron pasar de contrabando, los totales resultan interesantes y plantean numerosos interrogantes en torno a las redes que mantuvieron, a pesar de las dificultades y de las debilidades del abastecimiento, un hilo de lecturas en común en forma de transferencia cultural sostenida.

15 Un detallado análisis de los negocios de los libreros sevillanos a finales del XVI en González Sánchez, Carlos A., y Maillard Álvarez, Natalia: Orbe tipográfico. El mercado del libro en la Sevilla de la segunda mitad del siglo XVI, Trea, Gijón, 2003. 
LIBROS ENVIADOS EN EL NAVÍO DE HONDURAS (1557-1700)

\section{TABLA II}

CARGADORES DE LIBROS EN EL NAVÍO DE HONDURAS

\begin{tabular}{cc} 
Años & Cargadores que registran libros \\
\hline $1538-1550$ & - \\
$1551-1560$ & 12 \\
$1561-1570$ & - \\
$1571-1580$ & - \\
$1581-1590$ & 3 \\
$1591-1600$ & 6 \\
$1601-1610$ & 68 \\
$1611-1620$ & 6 \\
$1621-1630$ & 7 \\
$1631-1640$ & 9 \\
$1641-1650$ & 2 \\
$1651-1660$ & 1 \\
$1661-1670$ & 3 \\
$1671-1680$ & 10 \\
$1681-1690$ & 4 \\
$1691-1700$ & - \\
\hline Total & 130
\end{tabular}

Total

130

TABLA III

CAJONES DE LIBROS ENVIADOS EN EL NAVÍO DE HONDURAS

Años

Cajones enviados a Honduras

\begin{tabular}{lr}
\hline $1650-1659$ & - \\
$1660-1669$ & 15 \\
$1670-1679$ & 83 \\
$1680-1689$ & 38 \\
$1690-1699$ & 5 \\
\hline
\end{tabular}

Total

141 


\section{Análisis de los envíos: libros en red}

La red de hombres hace posible la red de libros en circulación (tabla IV). Los circuitos y las rutas de las mercancías más habituales marcan el territorio de abastecimiento y los cauces por los cuales llegaban los libros a destino. Los puertos y caminos más transitados eran los que en primer lugar recibían los beneficios de las novedades impresas destinadas a una vasta clientela de lectores coloniales. Es el caso de Puerto Caballos, convertido en un punto clave de los circuitos mercantiles y polo de atracción para los negocios.

La red de intereses tejida en torno a las clientelas comerciales es clave para comprender las bases de distribución, las rutas y los mercados. Los mercaderes dependían de los intereses de los propietarios de la tierra y de la burocracia de la Corona, implicados de forma decisiva en la explotación de los recursos agrícolas a través del tributo indígena. Estas redes comerciales permitieron el abastecimiento de libros allí donde las deficientes estructuras de distribución a través de la librería americana no llegaban, en lugares donde toda la infraestructura para el negocio del libro, aún existiendo demanda, no se había consolidado. ${ }^{16}$

En los primeros envíos analizados de 1557 se aprecia una intervención de mercaderes como Alonso de la Aguila, que recibió unas horas en romance y "30 docenas de cartillas", enviados por una compañía sevillana que declaró además tinta, cañones, escribanías y papel. Era lo más frecuente, pues el mercader sevillano Juan Fernández de Honduras también remitió 30 "docenas de cartillas" en 1557 a encomenderos de Puerto Caballos. En conjunto, en ese mismo año pudimos localizar seis envíos con cartillas que suman en total 5.196 ejemplares. En esa fecha igualmente, los libros declarados en doce envíos alcanzaban los 269 ejemplares. Las menudencias impresas ligadas a la educación y los textos necesarios para la liturgia son, en gran medida, los enviados con mayor frecuencia en ese momento. En esos comienzos de circulación del libro también es posible articular la red de intercambio a partir de conocidos como el clérigo Pedro de Cabrera, que remitió desde Sevilla a Francisco Marroquín, obispo de Guatemala, un "libro de pergamino de tinieblas" y también varios libros de música al

16 Este problema es tratado en Rueda Ramírez, Pedro: "Mercaderes y libros en la Carrera de Indias a finales del reinado de Felipe II", en $V$ Reunión Científica de la Asociación Española de Historia Moderna: Felipe II y su tiempo, José Luis Pereira Iglesias (coord.), Universidad; Asociación Española de Historia Moderna, Cádiz, 1999, págs. 565-572. 
doctor Cota, ${ }^{17}$ tanto manuscritos como impresos, del tipo de los "dos cuerpos de libros de música de [Cristóbal de] Morales en uno". Esta forma de envíos, con lotes pequeños mandados por mercaderes bien a destinatarios concretos o en una venta de otro tipo, es el caso de los "quatro libros flos sanctorum catorce ducados" y "quatro misales diez y seis ducados" remitidos por Hernando de Torres al jubetero Juan Sedano, vecino de Honduras, que los recibió en 1593 junto a un lote de azafrán, hilo portugués, lancetas, cintas, sombreros, agujas, botones y calzas de lana. ${ }^{18}$

A principios del XVII detectamos negocios librarios de mayor calado. El caso de Pedro de Lyra es ejemplar. Aparece citado como destinatario de cajones de libros de los navíos de Honduras desde 1608 a 1640 y nos servirá para trazar la tipología de las modalidades del tráfico. Lyra era regidor de Guatemala y uno de los siete mercaderes con un mayor capital de la ciudad en 1623. ${ }^{19}$ En 1614 una relación de méritos da cuenta de que "a casi treynta años que paso de los reynos de España a estas partes". Vivió prácticamente toda su vida en Santiago de Guatemala y estuvo allí "con su cassa y familia teniéndola de las mas principales de esta ciudad en la qual a tiempo de seis años que sirbe el oficio de regidor y de familiar del sancto Oficio". ${ }^{20}$ Este peninsular dedicado a una intensa actividad comercial contaba en su declaración de bienes, demandada por la Corona, que su patrimonio se formó "enviando mi hacienda y arriesgándola destas provincias a los reinos de España y del Perú y a la ciudad de México y a la Puebla de los Ángeles." ${ }^{21}$ Era el radio de acción de los mercaderes de Santiago de Guatemala que controlaban el negocio de la exportación del cacao y el añil, así como los créditos a obrajeros a través de censos.

17 Archivo General de Indias (AGI), Contratación, 5537, 1. 2, f. 270. En 1563 el doctor Cota declaró ser vecino de Santiago de Guatemala, hijo de Luis González y de María Estévez, y que pasó como pasajero con Pablo Cota, hijo suyo y de doña Francisca de Monzón, a Guatemala.

18 AGI, Contratación, n. 1, r. 7, f. 26r. El Flos sanctorum es, con bastante probabilidad, el libro de Alonso de Villegas del que se enviaron cuatro partes. Los misales son un texto clave en la liturgia, se trata, en este caso, de los denominados libros del nuevo rezado tras las reformas emprendidas tras el Concilio de Trento, que supusieron una renovación de los misales, breviarios y otros similares. Un estudio detallado de su evolución en Righetti, Mario: Historia de la liturgia. Edición española preparada por Cornelio Urtasun Irisarri, Biblioteca de Autores Cristianos, Madrid, 1955. La circulación de estos libros es analizada por Moll, Jaime: "Plantino, los Junta y el 'Privilegio' del Nuevo Rezado", en: Simposio internacional sobre Cristóbal Plantino, Universidad Complutense, Madrid, 1990, págs. 9-23.

19 Peña, José F. de la, y López Díaz, María Teresa: "Comercio y poder: Los mercaderes y el Cabildo de Guatemala, 1592-1623”, en Miño Grijalva, Manuel (ed.): La formación de América Latina en la época colonial, El Colegio de México, México, 1992, pág. 130.

20 AGI, Patronato Real, 86, n. ${ }^{\circ}$ 4, r. 3. Relación de méritos y servicios de Pedro de Lyra, 1614.

21 Peña, José F. de la, y López Díaz, María Teresa: "Comercio y poder...", pág. 141. 
Lyra era el destinatario de buena parte de los envíos de libros a Guatemala en esos años, su faceta de prestigio quedaba cubierta por su papel como familiar de la Inquisición y su excelente posición económica en la sociedad colonial le convirtieron en un intermediario habitual. En 1608 los Carmona le enviaron un lote que iba por cuenta y riesgo de "un fraile que conoce el dicho Pedro de Lira que nosotros no sabemos el nombre" con 24 títulos de obras religiosas, fundamentalmente sermonarios. Da cuenta, como dato interesante, del precio de 24 reales "por la caxa en que van estos libros", ${ }^{22}$ indicador de su papel como intermediario.

Los Carmona también cargaron en 1608 un total de 47 títulos (281 ejemplares) que se corresponden con un envío para dos destinatarios. En este caso debían entregarse en el puerto de Santo Tomás de Amatique. Afirmaban los Carmona que los libros "me envío de Salamanca el pe maestro Fr. P. ${ }^{\circ}$ de Ledesma por cuya quenta y riesgo van", algo lógico, pues llevaban 167 tomos de la Suma de Ledesma (entre primeras y segundas partes). Ahora bien, también portaba "asimismo dos cajas de libros que le envíamos consignadas al dicho Pedro de Lira de lo proçedido del añir que nos envío registrado el año pasado" de 1606 y "estas dos cajas van por quenta y riesgo del dicho Pedro de Lira". De todos modos, en el detalle del cajón se indicaba una noticia interesante, pues las dos cajas últimas "me envío el padre fr. Domingo Rosales para que la envíe al dicho Pedro de Lira”. Esto es, tanto Carmona como Lyra eran intermediarios que hacían llegar a Guatemala los libros de Ledesma y de Rosales.

En 1609 Cristóbal Barrionuevo le registró un lote a Pedro de Lyra en Guatemala de "lo procedido de los veynte caxones de añir que le inbio" del que tiene "quenta corriente". Era un lote comercial de 57 títulos (185 ejemplares) con una selección de libros religiosos y algunos títulos de literatura como una "toledana discreta" ${ }^{23}$ Un texto un tanto singular del religioso Eugenio Martínez (O.Cist.) que llevaba el título de Genealogía de la toledana discreta. En la obra se desgrana en treinta y cuatro cantos una extensa y abigarrada versificación de aventuras caballerescas. Un libro que, en opinión de Pantoja Ribero, "pertenece a un género híbrido que mezcla los libros de caballerías y la épica culta renacentista cuando ya ambos filones narrativos han entrado en franca decadencia". ${ }^{24}$

22 AGI, Contratación, 1153B.

23 AGI, Contratación, 1154A.

24 Martínez, Eugenio: Genealogía de la toledana discreta (Toledo, 1604) [en línea], ed. y notas de Juan Carlos Pantoja Rivero, Universidad de Valencia, Valencia. http://parnaseo.uv.es/ Tirant/Butlleti.5/Toledana/toledana_indice.htm. 
En 1609, Juan Cascajo carga libros para entregar en Puerto Caballos a Pedro de Lyra para que hiciera la voluntad de "Juan Cascajo conforme auisa por sus cartas". El lote comprendía 39 títulos (159 ejemplares), la mayoría religiosos y textos de liturgia con "Diez y seis misales quarenta y nueue breuiarios y cinquenta dos diurnos del usso y reçado de la orden de St. Domingo siendo general el Rmo. Pe Jabier impressos todos en Roma anno de mill y seiscientos y tres y seiscientos y quatro y seiscientos y cinco". Aunque también declaró un libro de éxito "llamado don Quixote author Miguel de Cerbantes Saauedra impresso en Madrid año de mill y seiscientos y ocho". En 1613 recibió un lote de libros religiosos tan especializado que debió de responder a una petición concreta gestionada por los mercaderes sevillanos Bartolomé y Alonso Carmona Tamariz. En este caso llevaba obras recién publicadas, como las "Declaraciones de 12 lugares de la escritura por el pe Alua cartujo $4 .^{\circ}$ nuevo" que hace referencia a las Selectae annotationes et expositiones in varia utriusque testamenti de Juan de Alba (Valencia, 1613), o bien el asiento de la " $2 .^{\circ}$ parte de los sermones del obispo de Astorga fo" que es la Segunda parte de los Sermones y discursos (Valencia 1611) de Antonio de Cáceres y Sotomayor. También se incluían algunos textos que habían pasado el filtro expurgatorio del recién aparecido índice de libros prohibidos de 1612, como la "Bibliotheca sactorum patrum de las nuevas emendadas conforme al catalogo por el pe $\mathrm{Ju}^{\circ}$ de Pineda en 6 tomos".

En las décadas de los veinte y treinta el intermediario habitual de Lyra era el mercader Juan Fernández Jurado. Así, en 1628 le remitió dos cajones de libros y en 1633 tres cajones con "libros que se abrieron en el aduana y se uieron." ${ }^{25}$ Para entonces Lyra tenía parte de su patrimonio en juros situados sobre el almojarifazgo y las almonas (fábricas de jabón) de Sevilla y dio orden a Fernández Jurado para invertir lo procedido de estas rentas (pero no el principal) en mercancías que fueron remitidas a Santiago de Guatemala. ${ }^{26} \mathrm{El}$ negocio era redondo, pues mantenía seguro el capital y, a la par, con los beneficios conseguía nuevos bienes para negociar. El plus añadido de ingresos se lograba con la venta de estas mercancías, incluidos los libros, a la llegada de la nao de Honduras a tierras centroamericanas.

En 1640 iban registrados dos cajones de libros "para dar y entregar a doña Catalina de Valdés y Caicamo, vecina de Santiago de Guatemala,

25 AGI, Contratación, 1177 y 1179. "N. S. de la Candelaria", f. 19.

26 Peña, José F. de la y López Díaz, María Teresa: “Comercio y poder...”, pág. 143. 
viuda de Pedro de Lyra, vecino y regidor." ${ }^{27}$ A Lyra le enviaron mercancías y lotes de libros particulares, mercaderes, libreros como el impresor sevillano Alonso Rodríguez Gamarra, que aprovechó el mercado de Guatemala en 1613 enviando a Lyra un lote de 295 ejemplares, aunque 150 de ellos son sermones sueltos. En la misma remesa también van menudencias con "quatro resmas de cartillas, coplas y libritos para niños de la escuela." ${ }^{28}$

El papel de Lyra como factor es similar al de otros muchos españoles de Centroamérica que actúan por cuenta de otros comerciantes o de una compañía, por tiempo determinado, siguiendo las indicaciones recibidas en la correspondencia y a cambio de una comisión, variable según el riesgo, las condiciones de recepción y envío, etc. Tan sólo conservamos algunas cartas de factores, como las que desde Guatemala envió el factor Pedro Herranz a Francisco Eslam de Flores en 1679 y 1680, en las que el primero indicaba las dificultades de venta y daba cuenta de los beneficios. Uno de los párrafos en los que se ocupa de la venta de unas plumas no tiene desperdicio pues indica Herranz que "las que Vmd. me remitió blancas vendí con los esparragones, fiadas a pagar para Navidad de este año, a tres reales los esparragones y los libros con $70 \%$ del costo principal de España". ${ }^{29}$ El beneficio podía ser, por lo tanto, realmente sugestivo para los intereses de los mercaderes españoles.

El importante mercader Francisco de Jerez Serrano aparece muy ocasionalmente como intermediario en el negocio de libros, a pesar de ser un comerciante muy destacado que afirmó haber "tenido tratos gruesos, enviando a Castilla cantidad de tinta y teniendo retorno a ella de cargazones, las cuales dentro de mi casa en el almacen las he vendido y beneficiado" ${ }^{30}$ Tan sólo encontramos en 1621 a Juan de Ocaña, un intermediario que también envió libros a Puebla de los Ángeles, registrando un lote de 32 títulos (con 139 ejemplares) al "mayordomo de la Catedral de Guatemala" que no es otro que nuestro comerciante y regidor Francisco de Jerez Serrano, un peninsular sólidamente establecido en la ciudad de Santiago. El lote presenta un rasgo destacado ya que contiene algunos libros que debieron interesar notablemente como "una istoria de Guatimala", junto a un lote de lite-

27 AGI, Contratación, 1184. "N. S. de la Candelaria”, f. 20v.

28 AGI, Contratación, 1159. "San José", f. 30.

29 Carrasco González, M. ${ }^{a}$ Guadalupe: Los instrumentos del comercio colonial en el Cádiz del siglo XVII (1650-1700), Banco de España, Madrid, 1996, pág. 76.

30 Peña, José F. de la, y López Díaz, María Teresa: “Comercio y poder...”, pág. 144. 
ratura de entretenimiento que contenía comedias ("Diez partes de comedias de Lope", novelas ("Dos del premio de la constançia, Uno la uida del escudero, Seis de la ssabia flora, Dos nobelas de cerbantes, Seis del marido examinado") y obras en verso ("Dos justa poetica de ssan ysidro, Un rromançero general"). ${ }^{31}$

La circulación de libros en áreas desabastecidas dependía, como vamos viendo, de los mercaderes. La red de caminos facilitaba la salida de la cosecha hacia puertos como el de Trujillo, ya que transportar a San Juan de Ulúa "costaría más de lo que vale y sería ymposible aber requas ni carruaje que lo trajinase con que pareze ser forçoso aberse de traer por la mar con más defensa que la que asta aquî́". Este testimonio anónimo y sin fecha declara los productos de exportación con los que se negociaba: "La cosecha de Honduras montara cada año 3.000 cajones de añil, 16.000 queros, 600 quintales de çarçaparrilla sin mucha cantidad de achiote, cacau y alguna plata que todo se junta en el puerto de Trujillo". ${ }^{32}$ Precisamente a esta ciudad iban en 1601 mercancías registradas por Fernando de Palma, cargador que no dejaba pasar la oportunidad de enviar junto a arrobas de aceite, bonetes de clérigo o servilletas, un "flor satorum de Villegas y unas oritas de devoción." ${ }^{33}$ Este parece un negocio claro. Veamos otro caso: el clérigo Pablo de Villalobos recibió en Trujillo 37 ejemplares de diez títulos distintos. Entre ellos 24 "oratorios de Fr. Luis [de Granada]", precisamente dos docenas, unidad de medida por excelencia de este tipo de libros de devoción. También recibió "dos libros del pícaro" que es la manera de asentar el libro de Mateo Alemán más difundido en América, el Guzmán de Alfarache, y dos ejemplares de la Filosofía secreta de Juan Pérez de Moya. ${ }^{34}$ Es un caso probable de actividad comercial a través de este clérigo, que, de paso, consiguió algunos libros para sí mismo y vendió o distribuyó el resto. Estas obras se podían conseguir con facilidad en el mercado librario sevillano.

Las librerías más destacadas actuaron como almacenes de libros para el Nuevo Mundo, a la calle Génova de Sevilla llegaban cajones enviados desde todas partes. Los mercaderes de libros sevillanos vinculados al tráfico americano son los más destacados y, en cierta medida, actuaban tratando a la mercancía libraria en régimen de "monipolio" tal y como lo

31 AGI, Contratación, 1170A. "San Francisco", f. 105.

32 AGI, Contratación, 4900. s/f.

33 AGI, Contratación, 1140A." Santa Ana", f. 90.

34 AGI, Contratación, 1141. "N. S. del Rosario", f. 39. Año 1602. 
define Alejo Venegas al referirse a "la compra en grueso de una mercaduría que compra uno o dos o tres para darla después por menudo a los mercaderes circunforáneos". ${ }^{35}$ Este menudeo escanciado en los registros que vemos es muy revelador de los abundantes resquicios de circulación del libro. El librero conseguía colocar la mercancía y lograba una distribución extensa en zonas en las que no había competencia. Estos libros tuvieron, a buen seguro, unas considerables posibilidades de circulación ante la demanda de impresos, un bien siempre escaso y apetecible en tierras centroamericanas.

El mercader Benito Rodríguez, vecino de Sevilla, era cargador en 1608 para el puerto de Trujillo. Uno de los lotes de mercancías que llevaba fue tasado en 660.000 maravedíes, y entre toda la variedad de telas, especias o productos de hierro encontramos "una resma de cartillas" valorada en 2.040 maravedíes. ${ }^{36}$ En otro registro distinto incluía un surtido de libros religiosos de 70 ejemplares muy frecuentes en los envíos a Nueva España, como los "seys oratorios de [Francisco Ortiz] Lucio a 6 reales cada uno", que el librero Antonio de Toro tasó en su conjunto en 1.050 reales. ${ }^{37}$

En 1608 llegó al Puerto de Santo Tomás el navío "Nuestra Señora de los Remedios" con una suculenta carga de libros, ya que once cargadores los habían registrado en Sevilla. Andrés París era uno de ellos. El registro constaba de una caja con una muy notable variedad de resmas, docenas y ejemplares de libros. Es conveniente anotarlo completo:

"Dos resmas de cartillas a 54 reales en 108 reales.

Seis resmas de catones y coplas del marque [sic] de Mantua y de Sant Alejo y de otras coplas diferentes a 20 reales resma en 120 reales.

Cuatro docenas de oratorios de frai Luis [de Granada] a 30 reales docena en 120 reales. Tres docenas de Romanceros a 16 reales docena en 48 reales.

Una suma de [Bartolomé de] Medina en 12 reales.

Diez libros de la conquista de Sevilla en $2 \frac{1}{2}$ reales en 25 reales. ${ }^{38}$

Un libro de comedias en seis reales.

35 Venegas del Busto, Alejo: Agonía del tránsito de la muerte; suivi de Breve declaración de las sentencias y vocablos obscuros que en el libro de la muerte se hallan, ed. Marc Zuili, Paris, 2001, pág. 628.

36 AGI, Contratación, 1153B. "N. S. de la Antigua”, f. 28r.

37 Ibídem, f. 38r.

38 El libro es un extenso poema épico de Juan de la Cueva (1550-1609): Conquista de la Betica. Impresso en Seuilla: en casa de Francisco Perez, 1603. Un texto en el que se canta "la restauracion y libertad de Seuilla por el Santo Rey Don Fernando” al conquistarla en 1248. 
Seis artes de Antonio [de Nebrija] a $21 / 2$ cada una en 15 reales.

Cuatro docenas de librillos de doctrina cristiana 8 reales docena en 32 ". ${ }^{39}$

El surtido de "coplas", romanceros y comedias era puro entretenimiento. También llevaba libros educativos como las cartillas, las doctrinas y las Introductione de Nebrija, estas últimas para el estudio de los rudimentos del latín. Alguna de las obras como los "diez libros de la conquista de Sevilla" iba, probablemente, por su buen precio y su carácter de composición en verso, pues casi todo lo de entretenimiento que se incluía en el envío era poesía. La lectura de la narración épica de la conquista de Sevilla en el otro lado del Atlántico debió resultar una distracción de deleite e incluso una lectura de asimilación al comparar la "recuperación" de la reconquista con el proceso colonial. En cualquier caso, el uso de los temas históricos por la poesía épica fue algo común en la descripción de la conquista americana.

En este navío también el cargador París registró libros para el deán de la Iglesia de Guatemala, Felipe Ruiz del Corral. Con anterioridad, en 1628, le había remitido a este deán otros dos cajones de libros. ${ }^{40}$ Como se ve, los intermediarios solían actuar de forma reiterada, lo que da idea de la existencia de redes consolidadas, las únicas que podían hacer viables los envíos a estos territorios.

\section{Los envíos a particulares}

El mercader Pedro de Mendoza aparece como intermediario al mandarse libros para particulares. Tenemos localizadas 12 hojas de registro que contienen libros para entregar en Guatemala, en los años comprendidos entre 1593 y 1604. En estos casos son pequeños lotes, como los que

39 AGI, Contratación, 1153B. "N. S. de los Remedios", f. 19r. Las resmas de menudencias en "coplas del marque [sic] de Mantua y de Sant Alejo y de otras coplas diferentes" forman un lote de 3.000 pliegos impresos. Tanto el Marqués de Mantua como la Vida de San Alejo tienen una larga vida editorial. Puede seguirse su trayectoria inicial en las prensas en Rodríguez-Moñino, Antonio: Nuevo diccionario bibliográfico de pliegos sueltos poéticos (siglo XVI). Edición corregida y actualizada por Arthur L.-F. Askins y Víctor Infantes, Castalia, Madrid, 1997.

40 Le envían en 1633 un lote de 23 títulos de obras de teología y derecho, valorados en 600 reales. En otro registro distinto se remitió un cajón más del que no se especifican los títulos, si bien alcanzan un valor de más de 800 reales, muy probablemente una continuación del envío anterior. AGI, Contratación, 1179. Con anterioridad le enviaron dos cajones de libros sin especificar títulos. AGI, Contratación, 1177. 
consignó al licenciado Pedro Mallén de Rueda, presidente de la Audiencia de Guatemala, con el "De natura noui orui" [de José de Acosta], un "calendario perpetuo" y un "flos sanctorum de Toledo". En otro envío Mendoza cargó:

"Las concordancias de la Bliuia de Plantino. ${ }^{41}$

Las partes del maestro [Juan] Ybañez [de Deza y Flechilla] dos cuerpos.

Un [Alonso de Villegas] Flos sanctorum de Toledo tres cuerpos. ${ }^{42}$

Un derecho canonico [Corpus Iuris Canonici] tres cuerpos".

Estos cuatro libros se mandaron a Cristóbal Ibáñez (intermediario habitual de los envíos de Mendoza) junto a dos piezas de ruán, una libra de hilo primo y seis manos de papel. El lote fue pagado con parte de los "quinientos sesenta y tres queros al pelo y tres mill tostones" que envió Ibáñez a Mendoza. En 1602 mandó al beneficiado Antonio Jiménez un lote de ocho libros, la mayoría religiosos con la salvedad de "1 Momo", de León Batista Alberti en traducción de Agustín Almazán. En otras ocasiones, en el lote de mercancías iba algún libro. En dos registros aparece un solo título. En estos casos llevaron, respectivamente, "un libro de Plinio noui" y "un reportorio [de los tiempos] de [Jerónimo de] Chaves". ${ }^{43}$ Estos pequeños lotes, destinados con bastante probabilidad a particulares, dan cuenta de envíos bajo demanda o bien pequeñas bibliotecas que se remitían aprovechando los circuitos comerciales.

De forma breve pretendemos ofrecer varios casos de juristas que recurrieron a la Carrera de Indias para lograr lotes de libros. En 1606 se remiten libros jurídicos a Bartolomé de la Canal de la Madrid, fiscal de la Audiencia de Guatemala. El jurista Canal era un caso ejemplar de ascenso en la carrera burocrática y social, utilizando para esto último su matrimonio, que le permitió consolidar su situación al ligarse con una familia de conquistadores. En 1601 desempeñó el cargo de fiscal y lo encontramos en 1609 como oidor. Entre tanto recibió un lote de 34 títulos jurídicos, evidentemente para el ejercicio de su oficio. Ese mismo año, 1606, en el que los

41 Es un libro publicado en varias ocasiones en las prensas de Cristóbal Plantino: Concordantiae Bibliorum utriusque Testamenti Veteris et Novi. Antuerpiae, 1581. $4 .^{\circ}$ CCPB000184282-X.

42 Se trata de tres de las seis partes escritas en castellano. El nombre "Toledo" en el asiento puede referirse al lugar de edición, pues en la ciudad de Toledo imprimió varias partes Juan Rodríguez; aunque también el autor era "capellan de la Capilla Morçarabe de la Santa Iglesia de Toledo".

43 AGI, Contratación, 1099. "El Espíritu Santo”, ff. 166-170. 
libros se embarcaron en el navío "Nuestra Señora de la Rosa", escribió una carta solicitando una ayuda de costa, cuyo texto es revelador:

“...mi mujer que passo desta vida a la eterna a los quinze de julio... de seyscientos y seys y demás de la mucha soledad y trabajos en que yo e quedado con su muerte e quedado tan pobre y tan necesitado como es notorio... y tan empeñado que para cumplir el funeral y el anima de la dicha mi muger fue necesario buscar dineros prestado... y no tengo hazienda ni me a quedado con que poderlos pagar... suplicar a vra. real persona sea servido de hazerme merced de los dichos quatrocientos pesos por vía de ayuda de costa... en mi cabeza y por los días de mi vida." ${ }^{4}$

Lo sorprendente es que tras tantos empeños y penurias pudiera gastarse en libros nada menos que 1.800 reales. La carta busca, a todas luces, conseguir una de las ayudas dadas a hijos de conquistadores, sacando así partido de la viudedad por los días de mi vida. Más aún, si cabe, al encontrar en 1608 un envío para él de "una cama de madera dorada en cinco cajas" en la que instaló la "colcha de olanda" 45 de 20 ducados que le remitieron. El conjunto daba cuenta de un notable lujo en su alcoba.

Las clientelas asoman por doquier. Al oidor Rodrigo de Valcárcel le resultó fácil conseguir los libros que necesitaba. Le bastó acudir al alguacil de la Audiencia, un empleado que mantenía negocios con mercaderes sevillanos. Por ejemplo, actuaba de factor de las mercancías enviadas por Juan de Neve. No tiene nada de extraño que le facilitara al jurista la llegada de "un caxoncillo de libros para don R." de Balcalcer oydor de Guatemala", que iban en un envío de jerguetas, melinges, ruanes, medias e hilo de vela. ${ }^{46}$

El dominico Domingo de Rosales residía en 1606 en el convento de San Pablo de Sevilla (hospedería de los que iban o venían de América), desde donde envió 16 títulos, todos religiosos menos el Arte de Nebrija, a Guatemala. Con el objetivo de asegurar la entrega indicaba que se dieran:

“...a la persona que ordenare Sancho de la Raona, vecino de Guatemala, o el canónigo Sancho Rahona, su hijo, o el Pe Fr. Garçia de Lohaysa de la orden de santo Domingo o a la persona que tuviere horden de reciuir la ropa que fuere para el convento de Santo Domingo de Guatemala para dar y entregar al dicho Fr. Garçía de Loaysa dominico por cuyo riesgo va." ${ }^{47}$

44 AGI, Guatemala, 117, n. ${ }^{\circ} 22$. La petición lleva fecha de 1607, para entonces los libros debían estar ya en su poder. La flota de 1606 llegó a Veracruz el 9 de septiembre.

45 AGI, Contratación, 1153B. "N. S. de la Antigua", f. 218-219.

46 AGI, Contratación, 1177. "San Juan Bautista", f. 111v.

47 AGI, Contratación, 1149. "N. S. de Belén”, f. 26r. 
El cargador citó hasta cuatro posibles agentes que facilitaran la llegada de la remesa al destinatario final. Revelaba así la necesidad de contar o con una red de factores o bien con distintos conocidos que pudieran dar el siguiente impulso a la circulación de los impresos hasta su destino. Estas relaciones son la clave que sostenía algunos envíos como los "tres caxones de libros que contienen la Política de D. Juan de Solorzano" que remitió Fernando Bravo "para dar y entregar en la dicha provincia a D. Antonio de Lara oydor de Guatemala y en su ausencia a D. Juan de Esquivel fiscal de la dicha Audiencia". ${ }^{48}$ Era un libro muy interesante para los burócratas americanos pues se acababa de traducir y su contenido era clave para sostener el dominio de la Corona castellana en las tierras americanas.

Entre las obras embarcadas también se encontraban literarias. En una "memoria de los libros que van en una caxa para Guatimala encaminados al Sr. Don Mathias de Solis oydor" de 1621 se declaraban 34 títulos, con un lote muy variado de obras épicas, picarescas, pastoriles y comedias:

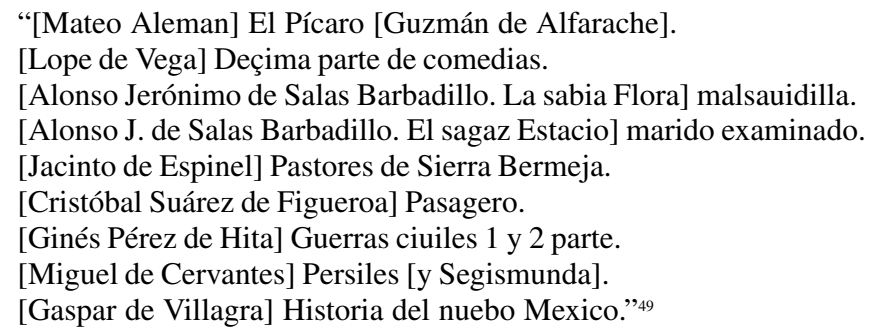

Es interesante constatar el gusto literario de algunos de estos burócratas, algo que no necesariamente se reflejaba en sus inventarios post-mortem. En este caso las lecturas del citado oidor combinan la prosa, la poesía y el teatro con un especial interés por libros publicados a principios del siglo XVII. Es aún más interesante si lo contrastamos con un envío comercial de 1590 en el cual las obras de entretenimiento tenían un cariz muy distinto. En la "Memoria de los libros que van para Indias", presentada por Juan Arias de Herrera, se anotaban 19 obras de historia y literatura, y tan

48 AGI, Contratación, 1196. "San Antonio de Padua”, f. 65. El envío de tres cajones con esta obra parece indicar que se trata de una distribución de un lote importante del libro de Solórzano Pereira, Juan (1575-1654): Politica indiana sacada en lengua castellana de los dos tomos del Derecho i gouierno municipal de las Indias Occidentales. En Madrid: por Diego Diaz de la Carrera, 1648. 2. CCPB000051960-X.

49 AGI, Contratación, 1170A. "San Francisco", f. 40r-v. 
sólo 4 de contenido religioso. Era, con bastante probabilidad, un surtido para la venta, que comprendía:

“[Alonso de Ercilla] La araucana p $\mathrm{p}^{\mathrm{a}}$ y $2^{\mathrm{a}}$ y $3^{\mathrm{a}}$ parte.

[Diego Ortuñez de Calahorra] Cauallero del Febo [Alcalá de Henares, 1580].

[Ludovico Ariosto] Orlando furioso.

Coloquios satíricos.

[Juan Rufo Gutiérrez] Austriada [Alcalá de Henares, 1586].

[Agustín Alonso] Bernardo del Carpio [Toledo, 1585].

[Jerónimo de Castilla] Florando de Castilla [lauro de caballeros. Alcalá de Henares, 1588].

Roncesvalles.

[Beatriz Bernal] Don Christalian [de España. Alcalá de Henares, 1587].

[Jerónimo Fernández] Don Belianis [Burgos, 1587].

[Lucas Rodríguez] Romancero historiado [Alcalá de Henares, 1585].

[Jerónimo de Contreras] Selva de aventuras [Valencia, 1589].”.

Estas obras literarias fueron, sin duda, degustadas por públicos diversos. El tráfico comercial de los libros de caballería (varios de los aquí citados editados en Alcalá de Henares pocos años antes del envío) se fue reduciendo pero no así la épica ni el romancero, que lograron un notable éxito comercial en el siglo XVII. En cualquier caso, denotan un circuito comercial para los libros de entretenimiento, que llegaron con relativa facilidad a tierras centroamericanas.

\section{Conclusiones}

La muestra de 52 registros de navíos de Honduras aquí analizados, que suponen un $20 \%$ del total, nos ha permitido detectar lotes de libros declarados como mercancías en 34 barcos, y en ellos localizar un total de 130 envíos. Este conjunto sirve para encontrar las claves del circuito de llegada de los libros, muy poco conocido, por medio de cargadores (comerciantes, libreros, particulares, etc.). Entre ellos destacan comerciantes como Pedro de Lyra, que mantiene una red de contactos para facilitar la llegada de lotes con regularidad. Los textos europeos embarcados permiten entender las relaciones de los colonos con la lectura, sus preferencias por la literatura devota contrarreformista, los libros para el aprendiza-

50 AGI, Contratación, 1089, n. 5-1, f. 47r. 
je en lengua vernácula y en latín, así como por obras de entretenimiento, ampliamente representadas en los envíos con comedias, libros de poesía y novelas.

El abastecimiento de libros en Honduras tuvo notables dependencias en cuanto al ritmo de llegada de las obras en los barcos de la Carrera de Indias, a las rutas de aprovisionamiento que facilitaban su circulación y las disponibilidades limitadas de conseguir las novedades recién publicadas. El libro en ningún caso estuvo ausente, al contrario. Los inventarios, los registros de carga de mercancías y otras fuentes nos informan del tráfico de esta mercancía cultural hacia Centroamérica desde fechas tempranas. Los impresos son productos de consumo vitales en la formación de las nuevas sociedades americanas. Los mecanismos comerciales de suministro a través de las rutas de la Carrera de Indias fueron un cauce continuo que permitió la consolidación del negocio del libro en ciudades como Guatemala. Tal como nos recuerda Luján Muñoz, "en toda situación colonial se produce un esfuerzo por reproducir la cultura material e inmaterial metropolitana; es decir, repetirla" o, en la cabeza de los protagonistas, continuarla, como él cita, por importación o duplicación. ${ }^{51}$

51 Luján Muñoz, Jorge: "Centro y periferia en el reino de Guatemala durante la dominación española", en Factores de diferenciación e instancias integradoras en la experiencia del mundo Iberoamericano, Real Academia de la Historia, Madrid, 1994, págs. 335-349 (cita de las págs. 341-342). 


\title{
Apéndice
}

\author{
TABLA IV
}

CARGADORES DE LIBROS EN EL NAVÍO DE HONDURAS

\begin{tabular}{|c|c|c|c|c|c|}
\hline Cargador & Legajo & Año & Menudencias & Títulos & Ejemplares \\
\hline Olmedo, Cristóbal de & 1.079 & 1557 & 20 gruesas de cartillas & - & - \\
\hline Caballero, Sancho & 1.079 & 1557 & 30 docenas de cartillas & - & - \\
\hline Vizcaya, Diego de & 1.079 & 1557 & & 2 & 3 \\
\hline Cabrera, Pedro de & 1.079 & 1557 & & 1 & 1 \\
\hline Cabrera, Pedro de & 1.079 & 1557 & & 5 & 69 \\
\hline Fernández de Honduras, Juan & 1.079 & 1557 & 30 docenas de cartillas & - & - \\
\hline Medina de Villavicencio, Juan & 1.079 & 1557 & 30 docenas de cartillas & - & - \\
\hline Medina de Villavicencio, Juan & 1.079 & 1557 & & 8 & 8 \\
\hline Medina de Villavicencio, Juan & 1.079 & 1557 & 83 docenas de cartillas & 2 & 184 \\
\hline Medina de Villavicencio, Juan & 1.079 & 1557 & 20 docenas de cartillas & - & - \\
\hline Torres, Francisco de & 1.079 & 1557 & & 2 & 2 \\
\hline Buyza, Francisco de & 1.079 & 1557 & & 2 & 2 \\
\hline Arias de Herrera, Juan & 1.089 & 1590 & & 24 & s.e. \\
\hline Macias, Diego & 1.092 & 1590 & & 1 & 12 \\
\hline Escovedo, García de & 1.092 & 1590 & & 1 & 1 \\
\hline Gómez Moreno, Alonso & 1.099 & 1593 & & 1 & 4 \\
\hline Torres, Hernando de & 1.099 & 1593 & & 2 & 8 \\
\hline Mendoza, Pedro de & 1.099 & 1593 & & 1 & 6 \\
\hline Mendoza, Pedro de & 1.099 & 1593 & & 1 & 6 \\
\hline Alofaz, Dionisio de & 1.099 & 1593 & & 9 & s.e. \\
\hline Solórzano, Andrés & 1.131 & 1599 & & 2 & 45 \\
\hline Rodríguez, Tomás & $1.140 \mathrm{~A}$ & 1601 & Media resma de cartillas & - & - \\
\hline Rodríguez, Benito & $1.140 \mathrm{~A}$ & 1601 & Media resma de cartillas & 8 & 52 \\
\hline Palma, Fernando de & $1.140 \mathrm{~A}$ & 1601 & & 2 & 2 \\
\hline Palma, Fernando de & $1.140 \mathrm{~A}$ & 1601 & & 8 & 41 \\
\hline Solórzano, Andrés de & $1.140 \mathrm{~A}$ & 1601 & & 10 & 39 \\
\hline Cuenca, Alonso de & $1.140 \mathrm{~A}$ & 1601 & & 11 & s.e. \\
\hline León, Manuel de & 1.141 & 1602 & & 10 & 37 \\
\hline Palma, Fernando de & 1.141 & 1602 & 200 papeles de estampas & 7 & 22 \\
\hline Carmona, Hernando y Bartolomé & 1.141 & 1602 & Una gruesa de cartillas & - & - \\
\hline Carmona, Hernando y Bartolomé & 1.141 & 1602 & & 26 & 26 \\
\hline Mendoza, Pedro de & 1.141 & 1602 & & 13 & 13 \\
\hline Mendoza, Pedro de & 1.141 & 1602 & & 8 & 8 \\
\hline Mendoza, Pedro de & 1.141 & 1602 & 500 estampas & 1 & 1 \\
\hline Lucena, García de & 1.142 & 1603 & & 1 & 24 \\
\hline
\end{tabular}


PEDRO RUEDA RAMÍREZ

\section{TABLA IV (continuación)}

\begin{tabular}{|c|c|c|c|c|c|}
\hline Cargador & Legajo & Año & Menudencias & Títulos & Ejemplares \\
\hline Carmona, Hernando y Bartolomé & 1.142 & 1603 & & 9 & 9 \\
\hline Carmona, Hernando y Bartolomé & 1.142 & 1603 & & 14 & 53 \\
\hline Solórzano, Andrés de & 1.142 & 1603 & & 11 & 31 \\
\hline Palma, Fernando de & 1.142 & 1603 & & 19 & 42 \\
\hline Mendoza, Pedro de & 1.142 & 1603 & & 10 & 10 \\
\hline Mendoza, Pedro de & 1.142 & 1603 & & 12 & 12 \\
\hline Mendoza, Pedro de & 1.142 & 1603 & & 11 & 11 \\
\hline Mendoza, Pedro de & 1.142 & 1603 & & 6 & 24 \\
\hline Mendoza, Pedro de & 1.142 & 1603 & & 26 & 26 \\
\hline Escobedo, García de & 1.142 & 1603 & & 1 & 12 \\
\hline Carmona, Hernando y Bartolomé & 1.144B & 1604 & & 1 & 30 \\
\hline Carmona, Hernando y Bartolomé & 1.144B & 1604 & & 17 & 61 \\
\hline Solórzano, Andrés de & 1.144B & 1604 & & 16 & 34 \\
\hline Monesterio, Juan de & 1.144B & 1604 & & s.e. & Una cajuela \\
\hline Rodríguez, Benito & $1.144 \mathrm{C}$ & 1604 & & 24 & 78 \\
\hline Palma, Fernando de & $1.144 \mathrm{C}$ & 1604 & & 52 & 262 \\
\hline Mendoza, Pedro de & $1.144 \mathrm{C}$ & 1604 & & 35 & 38 \\
\hline Mendoza, Pedro de & $1.144 \mathrm{C}$ & 1604 & & 24 & 28 \\
\hline Rosales, Fr. Domingo de (O.P.) & 1.149 & 1606 & & 16 & s.e. \\
\hline Carmona, Hernando y Bartolomé & 1.149 & 1606 & & 34 & 34 \\
\hline Pérez Cabrera, Ruy & $1.153 \mathrm{~B}$ & 1608 & & 1 & 494 \\
\hline Rodríguez, Benito & $1.153 \mathrm{~B}$ & 1608 & Una resma de cartillas & - & - \\
\hline Gómez Cornejo, Diego & $1.153 \mathrm{~B}$ & 1608 & & 155 & 155 \\
\hline Rodríguez, Benito & $1.153 \mathrm{~B}$ & 1608 & & 16 & 70 \\
\hline Mexía Farfán, Pedro & 1.153B & 1608 & & 9 & 55 \\
\hline Mexía Farfán, Pedro & $1.153 \mathrm{~B}$ & 1608 & & 14 & 20 \\
\hline Solórzano, Andrés de & $1.153 \mathrm{~B}$ & 1608 & & 10 & 18 \\
\hline Solórzano, Andrés de & $1.153 \mathrm{~B}$ & 1608 & & 10 & 16 \\
\hline Palma, Fernando de & 1.153B & 1608 & & 5 & 5 \\
\hline Palma, Fernando de & $1.153 \mathrm{~B}$ & 1608 & & 1 & 6 \\
\hline Carmona, Hernando y Bartolomé & $1.153 \mathrm{~B}$ & 1608 & & 47 & 281 \\
\hline Carmona, Hernando y Bartolomé & $1.153 \mathrm{~B}$ & 1608 & & 24 & 24 \\
\hline Núñez Barahona, Sancho & $1.153 \mathrm{~B}$ & 1608 & & 37 & 39 \\
\hline González, Licenciado Francisco & 1.153B & 1608 & & 24 & 36 \\
\hline París, Andrés & $1.153 \mathrm{~B}$ & 1608 & Menudencias varias & 7 & 150 \\
\hline Caballero Belmonte, Fernando & $1.153 \mathrm{~B}$ & 1608 & & 59 & 59 \\
\hline Palma, Fernando de & $1.153 \mathrm{~B}$ & 1608 & & 2 & 2 \\
\hline Palma, Fernando de & $1.153 \mathrm{~B}$ & 1608 & & 11 & 11 \\
\hline Palma, Fernando de & $1.153 \mathrm{~B}$ & 1608 & & 11 & 11 \\
\hline Barrionuevo, Cristóbal de & $1.153 \mathrm{~B}$ & 1608 & & 25 & 37 \\
\hline Barrionuevo, Cristóbal de & $1.153 \mathrm{~B}$ & 1608 & & 1 & 1 \\
\hline Ruiz Méndez, Asencio & $1.153 \mathrm{~B}$ & 1608 & $\begin{array}{c}100 \text { cartillas } \\
20 \text { manos de coplas }\end{array}$ & 2 & 13 \\
\hline Villalpando, Antonio de & $1.153 \mathrm{~B}$ & 1608 & & 1 & 6 \\
\hline Arias de Rabanal, Gómez & $1.154 \mathrm{~A}$ & 1609 & & 11 & 13 \\
\hline Palma, Fernando de & $1.154 \mathrm{~A}$ & 1609 & & 11 & 50 \\
\hline Barrionuevo, Cristóbal de & $1.154 \mathrm{~A}$ & 1609 & & 57 & 185 \\
\hline Carmona, Hernando y Bartolomé & $1.154 \mathrm{~A}$ & 1609 & & 8 & s.e. \\
\hline
\end{tabular}




\section{TABLA IV (continuación)}

\begin{tabular}{|c|c|c|c|c|c|}
\hline Cargador & Legajo & Año & Menudencias & Títulos & $s$ Ejemplares \\
\hline Cascajo, Juan & $1.154 \mathrm{~A}$ & 1609 & & 39 & 159 \\
\hline Carmona, Juan de y Bartolomé & $1.156 \mathrm{~A}$ & 1609 & & 8 & s.e. \\
\hline Barrionuevo, Cristóbal de & $1.156 \mathrm{~A}$ & 1609 & & 32 & 99 \\
\hline Barrionuevo, Cristóbal de & $1.156 \mathrm{~A}$ & 1609 & & 27 & 31 \\
\hline Gómez, Juan & $1.156 \mathrm{~A}$ & 1609 & & 17 & 17 \\
\hline Rodríguez Gamarra, Alonso & 1.159 & 1613 & & 29 & 295 \\
\hline Barrionuevo, Cristóbal & 1.159 & 1613 & & 17 & 17 \\
\hline San Angelo, Fr. Domingo de & 1.160 & 1613 & & 6 & 19 \\
\hline Palma, Fernando de & 1.160 & 1613 & & 23 & 23 \\
\hline Mexía, Fernando & 1.160 & 1613 & & 64 & s.e. \\
\hline Carmona, Alonso y Bartolomé & 1.160 & 1613 & & 20 & s.e. \\
\hline Lara, Juan de & $1.170 \mathrm{~A}$ & 1621 & & 34 & s.e. \\
\hline Ocaña, Juan de & $1.170 \mathrm{~A}$ & 1621 & & 32 & 139 \\
\hline Cerbellón, Gaspar & 1.173 & 1625 & & 106 & s.e. \\
\hline López de Calatayud, Antonio & 1.174 & 1625 & & 20 & s.e. \\
\hline Fernández Jurado, Juan & 1.177 & 1628 & & s.e. & Dos cajones \\
\hline Fernández Jurado, Juan & 1.177 & 1628 & & s.e. & Dos cajones \\
\hline Neve, Juan de & 1.177 & 1628 & & s.e. & Un cajoncillo \\
\hline Fernández Jurado, Juan & 1.179 & 1633 & & s.e. & Tres cajones \\
\hline Andrade, Enrique de & 1.179 & 1633 & & 21 & s.e. \\
\hline Arespacochaga, Francisco de & 1.179 & 1633 & & 23 & 23 \\
\hline Fernández Jurado, Juan & 1.179 & 1633 & & s.e. & Un cajón \\
\hline Andrade, Enrique de & 1.184 & 1640 & & 5 & s.e. \\
\hline David, Lanfran & 1.184 & 1640 & & s.s. $\mathrm{C}$ & Cinco cajoncillos \\
\hline Enríquez y Moncada, Pedro de & 1.184 & 1640 & & 14 & s.e. \\
\hline Enríquez y Moncada, Pedro de & 1.184 & 1640 & & 8 & s.e. \\
\hline Cuaca o Çuaça, Francisco & 1.184 & 1640 & & 10 & 118 \\
\hline Andrade, Enrique de & 1.185 & 1642 & & 3 & 23 \\
\hline Bravo, Fernando & 1.196 & 1650 & & 1 & Tres cajones \\
\hline Andrade, Enrique de & 1.200 & 1653 & & 6 & 12 \\
\hline Gárate y Francia, Juan, oidor & 1.207 & 1662 & & s.e. & Once cajones \\
\hline Escalante, Bernardo de & 1.209 & 1665 & & 1 & Un baúl \\
\hline Illanes, Juan de & 1.215 & 1669 & & s.e. & Tres cajones \\
\hline Hano y Carasa, Esteban & 1.227 & 1675 & & 15 & s.e. \\
\hline Segura, Pedro de & 1.227 & 1675 & & s.e. & Ocho cajones \\
\hline Illanes, Juan de & 1.227 & 1675 & & s.e. & Doce cajones \\
\hline Calvo de Lara, Alonso & 1.231 & 1678 & & s.e. & Ocho cajones \\
\hline Calvo de Lara, Alonso & 1.231 & 1678 & & s.e. & Dos cajones \\
\hline Ollo, Martín de & 1.231 & 1678 & & s.e. & Un cajoncillo \\
\hline Pérez de Garayo, Juan & 1.231 & 1678 & & 6 & 38 \\
\hline Pozo, José del & 1.231 & 1678 & & s.e. & Un baúl \\
\hline Pérez de Vera, Juan & 1.231 & 1678 & & s.e. & Seis cajones \\
\hline Vélez de Guevara, Salvador & 1.236 & 1680 & & 69 & - \\
\hline Ypensa, Fr. Ambrosio de & 1.244 & 1687 & & s.e. & 27 cajones \\
\hline González de Lucena, García & 1.244 & 1687 & & s.e. & $\begin{array}{l}\text { Dos cajones } \\
\text { Dos petacas }\end{array}$ \\
\hline Ypensa, Fr. Ambrosio de & 1.244 & 1687 & & s.e. & Un cajón \\
\hline Natividad, Fr. Francisco de la & 1.244 & 1687 & & s.e. & Seis cajones \\
\hline
\end{tabular}

